\title{
Commentary
}

\section{Investing in mental health}

D. Chisholm

\section{Why invest in mental health?}

Mental, neurological and substance-use disorders account for 9 out of the 20 leading causes of years lived with disability worldwide (more than a quarter of all measured disability) and $10 \%$ of the global burden of disease (which includes deaths as well as disability) $(1,2)$. A recent analysis by the World Economic Forum estimated that the cumulative global impact of mental disorders in terms of lost economic output will amount to US\$ 16 trillion over the next 20 years (3). Such an estimate marks mental health out as a highly significant concern, not only for public health but also for economic development and societal welfare.

Worldwide, current investments in mental health are extremely meagre. Many low- and middle-income countries allocate less than $2 \%$ - or even less than $1 \%$ - of their health budget to the treatment and prevention of mental disorders (4). Most of the funds that are made available by governments are specifically directed to the operational costs of specialized but increasingly outdated mental hospitals (which are commonly associated with isolation, human rights violations and poor outcomes). This inevitably curbs the development of more equitable and cost-effective community-based services.

It has been estimated that an integrated package of cost-effective mental health care and prevention can be delivered in community-based settings of low- and middle-income countries for US\$3-4 per capita per year (5).
The World Health Organization (WHO) recently set out 4 criteria against which public health investments are commonly made (6): the protection of human rights, including the right to health; the current and future (health and economic) burden of disease; the avertable burden of disease (resulting from the provision of cost-effective services); and the reduction of social inequalities, including access to essential health services. Application of these criteria to mental health revealed that a robust investment case can be made on the grounds of enhancing individual and population health and well-being, reducing social inequalities, protecting human rights, or improving economic efficiency.

The consequences of not investing in mental health are manifold and include:

- low rates of public awareness or understanding about the causes and impacts of better or worse mental health;

- low rates of detection, diagnosis, treatment and care for persons suffering from mental disorders and psychosocial disabilities;

- high costs to businesses and national economies as a result of diminished productivity.

\section{What to invest in for better mental health}

There is now a body of evidence demonstrating not only the efficacy of interventions but also their cost-effectiveness, affordability and feasibility. This information is available at the global level (i.e. for countries at different income levels) for alcohol use (as a risk factor for disease), epilepsy, depression and psychosis (Table 1) (5,6). A range of effective measures also exists for prevention of suicide, prevention and treatment of mental disorders in children (including appropriate immunization and proper nutrition/stimulation), prevention and treatment of dementia, and treatment of substance-use disorders. However, there is a relative dearth of cost-effectiveness data for these interventions and conditions; more information is needed for low- and middle-income countries.

It is also important to note that the onset or presence of a mental disorder increases the risk of disability and premature mortality from other diseases_-including cardiovascular disease, diabetes, HIV/ AIDS and other chronic conditionsdue to neglect of the person's physical health (by themselves, families or care providers), elevated rates of psychoactive substance use, diminished physical activity, an unhealthy diet and, in many cases, the side-effects of medication. Along with suicide, these chronic diseases produce a level of premature mortality far in excess of that of the general population; even in the relatively affluent context of Nordic countries the mortality gap has been estimated at 20 years for men and 15 years for women (7).

\section{How to invest in mental health: financing the development of service}

Mental health financing is a far-reaching topic that not only addresses the specific question of what services to purchase and how (purchasing function) but also 


\begin{tabular}{|c|c|c|c|c|}
\hline Disorder & Intervention & $\begin{array}{c}\text { Cost-effectiveness } \\
\text { (cost per healthy year of life } \\
\text { gained) }\end{array}$ & $\begin{array}{l}\text { Affordability } \\
\text { (cost per capita) }\end{array}$ & $\begin{array}{l}\text { Feasibility } \\
\text { (logistic or other } \\
\text { constraints) }\end{array}$ \\
\hline Epilepsy & $\begin{array}{l}\text { Treat cases with (first-line) } \\
\text { antiepileptic drugs }\end{array}$ & +++ & +++ & $\begin{array}{l}\text { Feasible in primary } \\
\text { care }\end{array}$ \\
\hline $\begin{array}{l}\text { Depression } \\
\text { (moderate-severe) }\end{array}$ & $\begin{array}{l}\text { Treat cases with (generic) } \\
\text { antidepressant drugs plus } \\
\text { brief psychotherapy as } \\
\text { required }\end{array}$ & +++ & ++ & $\begin{array}{l}\text { Feasible in primary } \\
\text { care }\end{array}$ \\
\hline \multirow[t]{2}{*}{ Harmful alcohol use } & $\begin{array}{l}\text { Restrict access to retail } \\
\text { alcohol } \\
\text { Enforce bans on alcohol } \\
\text { advertising } \\
\text { Raise taxes on alcohol }\end{array}$ & +++ & +++ & Highly feasible \\
\hline & $\begin{array}{l}\text { Enforce drink-driving laws } \\
\text { (breath-testing) } \\
\text { Offer counselling to } \\
\text { drinkers }\end{array}$ & ++ & ++ & $\begin{array}{l}\text { Feasible in primary } \\
\text { care }\end{array}$ \\
\hline Psychosis & $\begin{array}{l}\text { Treat cases with (older) } \\
\text { antipsychotic drugs plus } \\
\text { psychosocial support }\end{array}$ & ++ & + & $\begin{array}{l}\text { Feasible in primary } \\
\text { care; some referral } \\
\text { needed }\end{array}$ \\
\hline
\end{tabular}

Cost-effectiveness: $+++=$ very cost-effective (cost per healthy life year gained $<$ gross domestic product (GDP) per capita); $++=$ quite cost-effective (cost per healthy life year gained < 3 times GDP per capita); + = less cost-effective (cost per healthy life year gained > 3 times GDP per capita).

Affordability: $+++=$ very affordable (implementation cost $<$ US\$ 0.50 per person); $++=$ quite affordable (implementation cost $=$ US $\$ 0.50-1.00$ per person); $+=$ less affordable (implementation cost $>$ US\$1.00 per person).

more normative questions around how much should be raised for mental health service provision (collection function) as well as issues around equity of access and fairness of financial contributions (pooling function) (8). Financing is also intimately linked to other "building blocks" of the health system, notably the health workforce and service provision (see related commentaries in this supplement on service reorganization and human resources) $(9,10)$.

\section{Resource adequacy and needs}

A basic initial requirement of any mental health service development effort is to assess what resources are available and needed to deliver services to the target population and meet programme goals. A first step is to ascertain what financial and other resources are currently available (numbers of mental health professionals, inpatient beds, day care places, etc., as well as overall expenditures), followed by an appraisal of expected service needs and costs at target levels of service coverage in the population. Concerning health spending, WHO has developed tools for producing and analysing expenditures using the System of Health Accounts 2011 (11), which distributes expenditures for those diseases for which the country has data available (as a result, it is no longer recommended that countries produce disease- or condition-level sub-accounts). This means that it is vital to institute appropriate expenditure codes for mental health (and associated comorbidities) where they do not exist, and identify the key disease categories to be highlighted and used for policy (such as schizophrenia and other severe mental disorders since they are prominent, highly disabling and high-cost diseases that account for a significant share of overall mental health spending). WHO has also developed tools for undertaking integrated planning and costing of prevention and control efforts, including a mental health module of the inter-United Nations agency strategic planning tool called OneHealth (12). Use of such tools shows the budgetary implications of scaling-up prioritized, cost-effective interventions and reveals the returns on such investments (in terms of improved health).
Conclusion: All countries can undertake a resource needs assessment for better planning. Also, countries can develop and use the system of health accounts (11) to track mental health expenditures.

\section{Fair financing}

A fundamental concern underlying the drive towards universal health coverage relates to the high and potentially catastrophic cost of health care and treatment (to individuals and households). Direct, out-of-pocket payments represent a regressive form of health financing - they penalize those least able to afford care - and represent an obvious channel through which impoverishment may occur. Since mental disorders are typically chronic, usually require ongoing support, yet are often excluded from essential packages of care, they pose a particular threat to the economic wellbeing of households. Alongside ongoing efforts to monitor progress towards universal health coverage, it is therefore important for countries to better ascertain the extent 
to which mental health services are being directly financed by households in the form of out-of-pocket payments and what impact this is having on their income or economic welfare. Prepayment mechanisms such as national or social insurance represent a more equitable mechanism for safeguarding at-risk populations from the adverse financial consequences of mental disorders compared with out-of-pocket expenditures.

Conclusion: Resource-constrained countries can aim to ensure that priority interventions and services for persons with severe or highly-disabling mental disorders are included within national or social insurance schemes; wealthier nations can aim for comprehensive financial coverage.

\section{Purchasing}

How, where and to whom should available funds be most appropriately channelled for the purpose of delivering services to the population in need? A number of mechanisms are possible, each with their own underlying incentives, processes and implications. For example, mental health care providers can be paid on a "fee for service" basis, whereby a fixed price is agreed beforehand (for example, with social insurance or sickness funds) and reimbursed following the provision of a service, such as an outpatient consultation or an overnight inpatient stay. Here there is a clear incentive for providers to deliver as much care as they can, since the more they do the more they receive. This can lead to problems of over-provision or over-spend. By comparison, available funds can be directly allocated to government- or privately-run services at the sub-national level, most simply on a per capita basis (i.e. budgets are set in proportion to population size alone). Since the budget is fixed, there is strong pressure to keep overall expenditures under the set amount. However, such a mechanism overlooks the potentially large variations in mental health needs at the sub-national level: for example, regions with large cities might be expected to have a larger or more complex case-mix than more rural regions. Such variations can be accounted for via the development of resource allocation formulae.

Conclusion: All countries can review (and if necessary, revise) the way in which mental health care providers are paid to ensure that this is in the best interests of service-users and tax-payers / contributors.

\section{Funding the reorganisation of services}

A specific financing issue for mental health concerns the relocation of services and resources away from long-stay mental hospitals (which are commonly associated with isolation, human rights violations and poor outcomes) towards non-specialized health settings. Efforts to change the balance of mental health care are often hindered by a lack of appropriate transitional funding. Transitional or dual funding is clearly required over a period of time in order to build up appropriate community-based services before residents of long-term institutions can be relocated. It is therefore crucial to present an evidence-based case for relocating the locus of care not only on the grounds of equity, human rights and user satisfaction but also on the grounds of financial feasibility over a defined transitional period. A related issue concerns the shifting of responsibilities and associated funding from health to social care and housing systems. It is therefore important that sufficient social and financial protection measures are put in place, for example via payment exemption schemes for people meeting a certain threshold level of physical or psychosocial disability.

Conclusion: All countries can plan and make provisions for the gradual relocation of care from long-stay mental hospitals towards non-specialized health settings. Transitional funding is an important enabling lever for such a relocation of care.

\section{Who should invest} in mental health?

A multiplicity of actors can and should be investing more in promoting, protecting and restoring mental health, including individuals and families, local communities, businesses and employers, national governments, and international agencies. As the ultimate guardians of population health, governments have the lead responsibility to ensure that needs are met and that the mental health of the whole population is promoted. In order to address current shortcomings in the efficient and fair allocation of societal resources to mental health, governments and other stakeholders need to not only improve the coverage, depth and quality of services but also ensure that appropriate institutional, legal and financing arrangements are put in place to protect human rights and to address the mental health needs of the population. It is important to emphasize that such financial arrangements need to extend beyond the health sector alone, for example in the form of welfare support or housing.

\section{Key requirements and actions}

Based on this overview, the following actions can be highlighted as priority requirements.

- Set up mechanisms for tracking expenditure for mental health.

- Carry out a resource needs assessment based on locally agreed service coverage targets and intervention priorities.

- Allocate a budget that is commensurate with the agreed service targets and priority interventions.

- Provide transitional/bridge funding over a defined period of time to scale-up community-based services and downsize mental institutions (in parallel).

- Include defined priority mental disorders in the national/social insurance reimbursement schemes. 


\section{References}

1. Vos T, Flaxman AD, Naghavi M, Lozano R, Michaud C, Ezzati $M$, et al. Years lived with disability (YLDs) for 1160 sequelae of 289 diseases and injuries 1990-2010: a systematic analysis for the Global Burden of Disease Study 2010. Lancet. 2012;380:2163-96.

2. Murray CJ, Vos T, Lozano R, Naghavi M, Flaxman AD, Michaud C, et al. Disability-adjusted life years (DALYs) for 291 diseases and injuries in 21 regions, 1990-2010: a systematic analysis for the Global Burden of Disease Study 2010. Lancet. 2012;380:2197-223.

3. Bloom DE, Cafiero ET, Jané-Llopis E Abrahams-Gessel S, Bloom LR, Fathima S, et al. The global economic burden of non-communicable diseases. Geneva: World Economic Forum; 2011.

4. Mental health ATLAS 2011. Geneva: World Health Organization; 2011.

5. Chisholm D, Saxena S. Cost effectiveness of strategies to combat neuropsychiatric conditions in sub-Saharan Africa and South East Asia: mathematical modelling study. BMJ. 2012;344:e609.

6. Investing in mental health: evidence for action. Geneva: World Health Organization; 2013.
7. Wahlbeck K, Westman J, Nordentoft M, Gissler M, Laursen TM. Outcomes of Nordic mental health systems: life expectancy of patients with mental disorders. BrJ Psychiatry. 2011;199:453-8.

8. Mental health financing. Geneva: World Health Organization; 2005.

9. Ivbijaro G, Patel V, Chisholm D, Goldberg D, Khoja TAM, Edwards TM. Informing mental health policies and services in the EMR: cost-effective deployment of human resources to deliver integrated community-based care. East Mediterr health J. 2015; 21(7): 486-92.

10. Saraceno B, Gater R, Rahman A, Saeed K, Eaton J, Ivbijaro G, et al. Reorganization of mental health services: from institutional to community-based models of care. East Mediterr health J. 2015; 21(7): 477-85.

11. System of health accounts 2011. Geneva: World Health Organization; 2011 (www.who.int/health-accounts, accessed 14 February 2015).

12. OneHealth. Geneva: World Health Organization; 2012 (www. who.int/choice/onehealthtool, accessed 14 February 2015). 